\title{
Air Pollution and Respiratory Diseases During The Hajj Season in The Holy City of Makkah
}

\author{
Mukhtar Ikhsan*
}

Department Pulmonology and Respiratory Medicine Faculty of Medicine, Universitas Indonesia, Jakarta Pulmonology Department Faculty of Medicine, Syarif Hidayatullah State Islamic University, Jakarta

\begin{abstract}
Corresponding Author:
Mukhtar Ikhsan | Department

Pulmonology and Respiratory Medicine

Faculty of Medicine, Universitas Indonesia;

Pulmonology Department Faculty of

Medicine, Syarif Hidayatullah State Islamic

University, Jakarta I

mukhtar_ikhsan@yahoo.com
\end{abstract}

Submitted: Desember $27^{\text {th }}, 2021$

Accepted: January $18^{\text {th }}, 2022$

Published: February $28^{\text {th }}, 2022$

Respir Sci. 2022; 2(2): 124-131

https://doi.org/10.36497/respirsci.v2i2.37

\begin{abstract}
The holy city of Makkah is one of the big cities in Saudi Arabia that is densely populated, especially during the Hajj season. In recent years, air pollution in Makkah has been a growing problem due to construction activities, motor vehicle fumes, rising temperatures, rainfall and humidity. The higher the level of air pollution exposure, the more it has an impact on human health, especially the lungs and airways. The health impacts associated with air pollution include an increase in the incidence of respiratory infections, asthma, chronic obstructive pulmonary disease and other lung diseases. Better knowledge of the correlation between air pollution and lung and airway diseases will contribute to developing more strategies to reduce air pollution in the holy city of Makkah.
\end{abstract}

Keywords: air pollution, pilgrims, holy city of Makkah, respiratory disease

\section{INTRODUCTION}

Hajj is the fifth pillar of Islam. Around three million Muslims worldwide travel to the holy city of Makkah and perform various prayers in Makkah, Arafah, Muzdalifah, and Mina. During the pilgrimage season in the area, the human population increases significantly, and the activity is very high. Pilgrims spend several days on foot, driving cars, buses, trucks, and trains from one place to another, so these various activities produce a lot of air pollutants. In Makkah, the air quality data shows that air pollution during the Hajj season is among the worst in the world. This literature review will discuss the condition of air pollution and respiratory diseases in the holy city of Makkah during the Hajj season.

\section{AIR POLLUTANTS IN THE HOLY CITY OF MAKKAH}

\section{Particle}

In terms of health impacts, environmental damage, and impaired visibility, particulate matter (PM) is considered one of the most important air pollutants. Particle size, chemical composition, and pollution levels in the 
atmosphere are essential factors affecting human health. The size of the particles defines where they are deposited in the respiratory tract, while the chemical composition of the particles determines the sort of body response.

Habeebullah et al. conducted research in the Shebeka, Aziziah, Masfalah, and Awaly districts of Makkah. When compared to the proportion of total suspended particles (TSP), medium and coarse PM sizes are the most prevalent. ${ }^{1}$

Habeebullah conducted the investigation to assess the levels and chemical composition of TSP, PM10, and PM2.5. Total suspended particles, PM10, and PM2.5 were detected in Makkah from August 2012 to September 2013. Heavy metals, cations, and anions were also analyzed. The study revealed that a significant majority of PM is not caused by fossil fuels, but rather by particle resuspension, building, and demolition operations, as well as dust and sand particles driven by the wind. Research is needed to discover the specific source of PM in Makkah as part of efforts to enhance air quality in the city. ${ }^{2}$

Mohammed conducted a study to measure the spatial variation of PM10 in Makkah. In the north-western part of Makkah, PM10 levels are higher than in the southeast. The intensity of construction activities, transportation on highways, and city development in various locations in the central area of Makkah is the biggest contributor to the high levels of PM10. ${ }^{3}$

In the 2013 Hajj season, Khwaja et al. conducted a study to assess the air quality around the holy place of Makkah. They measured PM7, PM2.5, O3, and black carbon (BC) levels up to $9,433 \mu \mathrm{g} / \mathrm{m3}, 484$ $\mu \mathrm{g} / \mathrm{m3}, 444 \mathrm{ppb}$, and $468 \mu \mathrm{g} / \mathrm{m3}$, respectively. This average level has exceeded the standards of the World Health Organization (WHO) for PM10 and PM2.5. High traffic volume, construction activities, particle re-suspension, and geographical conditions (dry areas) are the main causes of air pollution. ${ }^{4}$

In the month of Ramadan and the Hajj seasons of 1424 and $1425 \mathrm{H}$, Seroji researched the levels of TSP, PM10, and PM2.5 in the air of Makkah and the Mina valley. The daily cycle of PM10 in the air is related to traffic activity patterns. During the pilgrims' presence in Mina, daily levels in the Mina valley air ranged from 191$262 \mu \mathrm{g} / \mathrm{m}^{3}$ exceeding the European standard of $50 \mu \mathrm{g} / \mathrm{m}_{3}$. Pollutants contain up to $34 \%-40 \%$ TSP. During the last ten days of Ramadan, TSP levels in Makkah reached $665 \mu \mathrm{g} / \mathrm{m}^{3}$ compared to the Saudi Arabian standard of $340 \mu \mathrm{g} / \mathrm{m}^{3}$. Chemical analysis of PM10 shows high levels of sulphate, ammonium, nitrate, and chloride. ${ }^{5}$

PM10 levels and their chemical composition were measured in six locations (Al-Haram, Arafah, Muzdalifah, Aziziyah, Al-Nuzhah, and Al-Awali) in a study conducted by Adly et al. They found that PM10 levels were highly correlated with levels of cadmium, chromium, arsenic, beryllium, and nickel. ${ }^{6}$

Siddique studied air pollution levels in Makkah during the Hajj seasons of 2012 and 2013. Pollutant levels on most pilgrims' travel routes have surpassed WHO 
standards for PM10 and PM2.5. High traffic volumes, construction activity, particle resuspension, and geographical circumstances all contributed to high levels of air pollution (dry areas). ${ }^{7}$

\section{Hazardous Gases}

Al-Jeelani conducted a study in Makkah during the Hajj season on January $14-25,2005$, to assess air quality due to emissions from the daily activities of pilgrims associated with increased transportation needs. Measurements of the levels of several harmful air pollutant gases and several meteorological parameters, including temperature, wind speed, and wind direction, were carried out. At the beginning of the day, residents' activities were traveling to work, and high traffic volume had affected pollutants. Carbon monoxide, $\mathrm{NO}$, and $\mathrm{NO}_{2}$ levels change throughout the day, whereas sulfur dioxide levels remain relatively constant. ${ }^{8}$

Habeebullah conducted a graphical approach to measure the main air pollutant sources near the Al-Haram Mosque in Makkah. Air pollutants considered in this study are nitrogen oxides (NOx), nitrogen dioxide $\left(\mathrm{NO}_{2}\right)$, nitric oxide (NO), carbon monoxide $(\mathrm{CO})$, sulphur dioxide $\left(\mathrm{SO}_{2}\right)$, ozone $\left(\mathrm{O}_{3}\right)$ and particulate matter with an aerodynamic diameter of 10 um or less (PM10). Polar plots, time variation plots and correlation analysis are used to analyse the data and identify the major sources of emissions. Most of the pollutants demonstrate high concentrations during the morning traffic peak hours, suggesting road traffic as the main source of emissions. The density of road traffic, resuspension of particles, and dust or sand particles blown by the wind are the main sources of pollutant emissions identified in Makkah. ${ }^{9}$

Simpson et al. conducted a research to investigate air pollution levels in Makkah during the Hajj season in 2012. The study discovered significant amounts of carbon monoxide (CO) and volatile organic compounds (VOC) throughout the pilgrimage routes, particularly in the Makkah tunnels. Benzene i-pentane is the most prevalent volatile organic compound. The primary sources of volatile organic compounds are automobile exhaust emissions, gasoline evaporation, liquefied petroleum gas, and air conditioning. ${ }^{10}$

Al-Jeelani conducted a study to measure the impact of motor vehicle emissions on air quality around the AlHaram Mosque in Makkah. Experimental, numerical, and statistical research were conducted. Several levels of harmful gases due to motor vehicle emissions are measured and analyzed. Research shows that the Masjid Al-Haram area has high levels of harmful gas pollutants. In addition, there was resistance to wind currents due to the height of the buildings around the Al-Haram Mosque. ${ }^{11}$

Research in the Taneem area by AlJeelani showed that levels of nitrogen oxides and carbon monoxide in the morning increased, while sulphur dioxide levels were relatively low and constant. In addition, photochemical reactions affect ozone levels. ${ }^{12}$ 


\section{Microbes}

Abdel Hameed conducted a study to measure levels of microbial air pollutants. Using the gravity method, microbial contamination in the air is collected from the main direction of the Al-Haram Mosque in Makkah. In all directions, the concentrations of bacteria, fungi and actinomycetes ranged from 1,470 21,800 CFU/m³, respectively; $44-572$ $\mathrm{CFU} / \mathrm{m}_{3}$ and $0.0264 \mathrm{CFU} / \mathrm{m}_{3}$. Bacterial levels differed significantly, and grampositive bacteria constituted $90-100 \%$ of the total bacterial isolates. Gamma proteobacteria are the common gramnegative bacteria, and Aspergillus is the predominant genus of fungi. Human activities have a greater influence on microbial levels than meteorological factors. ${ }^{13}$

Mohammed et al. conducted a study to measure particulate matter and biological contaminants in Makkah during the Hajj season of $1437 \mathrm{H}$. Microbial air samples were collected at five locations around the Al-Haram Mosque. The results showed that the percentage of grampositive bacteria ranged from $85-90 \%$ of the total bacteria isolated, while the percentage of gram-negative bacteria ranged from $5-9 \%$ of the total bacteria isolated. Spherical bacteria (cocci) were most commonly found in the grampositive group and made up $35-80 \%$ of the total bacteria isolated. Around the AlHaram Mosque in Makkah, humans are the main source of microbial air pollution. ${ }^{14}$

\section{Air Allergens}

The problem of allergic diseases has increased significantly over the last 50 years. Despite increasingly clear information on pathogenesis, risk factors, and treatment, allergies are on the rise. Allergens are proteins or glycoproteins that can induce a sIgE response. The top five inhalant allergens in the holy city of Makkah are the American cockroach, Dermatophagoides pteronyssinus, epithelia/cat hair, dessert palm pollen, and Dermatophagoides farina. ${ }^{15}$

\section{AIR POLLUTION AND RESPIRATORY DISEASES}

The respiratory tract is the primary portal of entry for air pollutants; consequently the respiratory effects of pollutants have been studied for decades. Table 1 provides examples of common respiratory conditions and outcomes that have been associated with air pollution exposure. Meanwhile, Table 2 provides examples of biomarkers of respiratory health or function that have been used in studies of the respiratory effects of air pollution. ${ }^{16}$

Examples of respiratory clinical effects associated with air pollution: ${ }^{16}$

1. Increased mortality of the respiratory disease

2. Increased incidence of respiratory tract malignancies

3. Increased incidence, prevalence, or frequency of exacerbations in the disease

4. chronic lung: asthma, COPD, and cystic fibrosis 
5. Increased incidence or severity of upper respiratory tract infections and

6. lower

7. Increased respiratory symptoms that affect the quality of life:

8. cough, phlegm, wheezing, shortness of breath, and runny nose

9. Increased incidence of preterm birth, low birth weight or growth inhibition

10. Impaired lung function growth in children

11. A temporary decrease in lung function

12. A transient decrease in lung function without symptoms, especially in

13. individuals who are susceptible (e.g., children with severe asthma)

14. The persistent or chronic decline in lung function (weeks, months, or years)

Examples of biomarkers of potentially adverse respiratory health effects: ${ }^{16}$

1. Elevated levels of airway inflammatory markers (e.g., PMN or cytokines in bronchial lavage or phlegm

2. Elevated levels of markers of airway inflammation or inflammation in:

a. The exhaled breath (e.g., increased acidity)

b. The exhaled breath condensate or increased FeNO in asthmatics)

3. Elevated blood markers in lung injury (e.g., 8-isoprostane, club cell

4. secretory protein)

5. Imaging evidence of lung injury or reduced lung volume

6. Decreased pulmonary gas exchange (e.g., DLCO, DLNO, PaO2, pulse

7. oximetry)

8. Improved airway responsiveness to nonspecific challenges
9. Increased airway hyper-reactivity in asthmatic patients

There are six types of substances present in the air that have a significant negative impact on public health: ozone, PM with different diameters - PM2.5 $\mu$, PM2.5-10 $\mu$, PM10 $\mu$, nitrogen dioxide, sulphur dioxide, carbon dioxide monoxide, and lead. Particular attention should be paid to small dust particles (PM10 and PM2.5) as they can penetrate the lower respiratory tract. The development and worsening of respiratory symptoms such as asthma, chronic obstructive pulmonary disease, respiratory infections, and lung cancer are all caused by air pollution. ${ }^{17}$

Research shows a relationship between air pollution and hospital admissions in adults due to Chronic Obstructive Pulmonary Disease (COPD). Increases in daily $\mathrm{NO}_{2}$ and particulate matter levels were associated with a $4.60 \%$ and $3.01 \%$ increase in COPD hospital admission rates, respectively, in Sydney. ${ }^{18}$ Another study on hospital admissions in Birmingham, England, reported an association between PM10 and rates of hospital admission due to pneumonia and mortality from COPD. ${ }^{19}$

Mohammed conducted a study in Makkah to evaluate the effect of a crushed mountain environment resulting in the dust on asthma patients. In the group exposed to a dusty environment, asthma symptoms worsened, lung function decreased, and the need for medication for relief and control of asthma attacks increased. ${ }^{20}$

Many previous studies have shown that respiratory infections increase during 
the Hajj season. Although upper respiratory tract diseases are prevalent, lower respiratory tract infections (pneumonia) can occur, and the latter is much more deadly than the former. The leading causes of illness include the influenza virus and other viruses and bacteria. The increase in respiratory infections during the Hajj season has severe implications for public health. It can lead to epidemics and adversely affect the economy due to increased health care costs, the need for hospital beds, and lost working days.

Strong evidence suggests an association between air pollution and the severity of illness associated with respiratory tract infections. Individuals with pre-existing lung disease are at higher risk. The majority of pilgrims are adults and the elderly. Complications, hospitalizations, and deaths from respiratory tract infections are most significant in the elderly and those with comorbidities. The disease that most often occurs during the Hajj season is a respiratory infection. The most common causes of respiratory tract infections are viral upper respiratory tract infections and bacterial respiratory infections. ${ }^{21}$

Sputum cultures were examined in outpatients for respiratory tract infections during the hajj season from 1991 to 1992. Three hundred and ninety-five samples were examined. Positive cultures were found in 118 specimens (30\%); The most common pathogens found were Haemophilus influenza, Klebsiella pneumonia, and Streptococcus pneumonia. In the same study, 761 throat swabs were performed for virus examination, $20 \%$ of which were positive, especially influenza and adenovirus. ${ }^{22}$

High-density areas pose a risk of local outbreaks and the worldwide spread of infectious agents. The study was conducted on 566 patients of Hajj pilgrims in $1434 \mathrm{H}$. Most of them (92\%) suffer from respiratory symptoms. ${ }^{23}$ Acute respiratory infections (ARI) are the leading cause of hospital admissions in Saudi Arabia during the Hajj season. ${ }^{24}$

In 2016, 2017 and 2018, the morbidity rate of Indonesian Hajj pilgrims due to a combination of various respiratory diseases was $49.0 \%, 51.95 \%$ and $49.31 \%$, respectively. Meanwhile, in 2016, 2017 and 2018, the mortality rate of Indonesian Hajj pilgrims due to respiratory diseases was $27,5 \%, 30,7 \%$ and $36.8 \%$, respectively. ${ }^{25-}$ 27

Elderly pilgrims are more susceptible to infectious diseases due to eating disorders, sleeping patterns, and damage to the immune system. In terms of nationality, the majority of infectious disease cases were discovered in Indonesian pilgrims (18.4\%), Saudi pilgrims $(17.1 \%)$, and Pakistani pilgrims $(11.8 \%){ }^{28}$

\section{CONCLUSION}

About three million pilgrims come to the holy city of Mecca every year to perform the pilgrimage. The increasing number of pilgrims is accompanied by an increase in daily activities and transportation needs. As a result, large 
amounts of solids, gases, microbes, and other pollutants are emitted into the air. Pollutants produced can cause various adverse effects on the health of pilgrims.

The respiratory tract is the main entrance point for air pollutants into the body. The effects of air pollution on respiratory tract diseases include an increase in asthma exacerbations, COPD and cystic fibrosis infections, hospital clinic visits, hospital emergency visits, hospital admissions, morbidity, and mortality. Every year, respiratory disease is one of the leading causes of illness and death among Indonesian pilgrims.

\section{REFERENCES}

1. Habeebullah T, Mohammed A, Morsy E. Spatial Variations of Atmospheric Particulate Matters in Makkah, Saudi Arabia . Environ Sci. 2014;3(10):156162.

2. Habeebullah TMA. Chemical Composition of Particulate Matters in Makkah - Focusing on Cations, Anions and Heavy Metals. Aerosol Air Qual Res. 2016;16(2):336-347.

3. AMF M, TM H, Essam A, Morsy E. Air Pollution in Saudi Arabia - Spatial Variation of PM10 in Makkah (KSA). Int J Agric Environ Res. 2016;2(2):116128.

4. Khwaja $H$, Aburizaiza OS, Siddique A, et al. An Assessment of Air Quality in the Surrounding Holy Places of Mecca, Saudi Arabia during Hajj. In: AGU Fall Meeting. San Francisco: American Chemical Society; 2014.
5. Seroji AR. Particulates In The Atmosphere Of Makkah And Mina Valley During The Ramadan And Hajj Seasons Of 2004 And 2005. WIT Trans Ecol Environ. 2011;147:319-327.

6. Adly HM, Saleh SAK, Saati AA, Fatani $\mathrm{SH}$. Airborne Carcinogenic Trace Elements Distribution Associated with Long Term Exposure in Makkah Population. Open Environ Res J. 2019;12(1):7-14.

7. Siddique A. Roads to Makkah: Ambient Air Quality and Personal Exposure Assessment During Ritual of Hajj. 2016;2016(1):EEPP1883.

8. Al-Jaeelani H. Evaluation of air quality in the Holy Makkah during Hajj season 1425 H. J App/ Sci Res. 2009;5(1):115121.

9. Habeebullah TM. An analysis of air pollution in Makkah - A view point of source identification.

EnvironmentAsia. 2013;6(2):11-17.

10. Simpson IJ, Aburizaiza OS, Siddique A, et al. Air quality in Mecca and surrounding holy places in Saudi Arabia during Hajj: initial survey. Environ Sci Technol. 2014;48(15):8529-8537.

11. Al-Jeelani HA, Al-Jeelani $H A$. The Impact of Traffic Emission on Air Quality in an Urban Environment. $J$ Environ Prot (Irvine, Calif). 2013;4(2):205-217.

12. Al-Jeelani HA. Air quality assessment at Al-Taneem area in the Holy Makkah City, Saudi Arabia. Environ Monit Assess. 2009;156(1-4):211-222. 
13. Hameed A, Habeeballah T. Air Microbial Contamination at the Holy Mosque, Makkah, Saudi Arabia. Curr World Environ J. 2013;8(2):179-187.

14. Mohammed AM, Attala OA, Habeebullah TM. PM10 and their biocontamination in Makkah Saudi Arabia- case study. Int J Biosens Bioelectron. 2017; Volume 2(Issue 1).

15. Tayeb MMS. The Common Aeroallergens in the Region of Makkah . J Fam Med Community Heal. 2014;1(3).

16. Drost EA. Validity and Reliability in Social Science Research. Educ Res Perspect. 2011;38(1):105-123.

17. Grzywa-Celińska A, Krusiński A, Milanowski J. "Smoging kills" - Effects of air pollution on human respiratory system. Ann Agric Environ Med. 2020;27(1):1-5.

18. Morgan G, Corbett S, Wlodarczyk J. Air pollution and hospital admissions in Sydney, Australia, 1990 to 1994. Am J Public Health. 1998;88(12):17611766.

19. Wordley J, Walters S, Ayres JG. Short Term Variations in Hospital Admissions and Mortality and Particulate Air Pollution . Occup Environ Med. 1997;54(2):108-116.

20. Mohamed NA, Al-Akad G. The influence of dusty environment (Makka city broken mountains) on bronchial asthma. Egypt $J$ Chest Dis Tuberc. 2014;63(2):305-308.

21. Razavi SM, Mardani M, Salamati P. Infectious Diseases and Preventive Measures During Hajj Mass
Gatherings: A Review of the Literature. Arch Clin Infect Dis 2018133. 2018;13(3).

22. El-Sheikh SM, El-Assouli SM, Mohammed KA, Albar M. Bacteria and viruses that cause respiratory tract infections during the pilgrimage ( $\mathrm{Haj}$ ) season in Makkah, Saudi Arabia PubMed. Trop Med Int Heal. 1998;3(3):205-209.

23. Bakhsh AR, Sindy AI, Baljoon MJ, et al. Diseases pattern among patients attending Holy Mosque (Haram) Medical Centers during Hajj 1434 (2013). Saudi Med J. 2015;36(8):962.

24. Ahmed QA, Arabi YM, Memish ZA. Health risks at the Hajj. Lancet (London, England). 2006;367(9515):1008-1015.

25. Pusdatin Kemenkes RI. Profil Kesehatan Indonesia 2016. Jakarta: Kementerian Kesehatan RI; 2017.

26. Kementrian Kesehatan RI. Profil Kesehatan Indonesia Tahun 2017. Jakarta: Kementerian Kesehatan RI; 2018.

27. Kementerian Kesehatan Republik Indonesia. Profil Kesehatan Indonesia Tahun 2018. Jakarta: Kementerian Kesehatan Republik Indonesia; 2019.

28. Asghar AH, Ashshi AM, Azhar EI, Bukhari SZ, Zafar TA, Momenah AM. Profile of bacterial pneumonia during Hajj - PubMed. Indian J Med Res . 2011;133(5):510-513. 